УДК 663.252.41: 575.22

03.00.00 Биологические науки

\section{ДНК-ПАСПОРТИЗАЦИЯ СОВРЕМЕННЫХ РОССИЙСКИХ СОРТОВ РИСА С ПРИМЕНЕНИЕМ SSR-МАРКЕРОВ ${ }^{*}$}

Супрун Иван Иванович ${ }^{1,2}$

к.б.н., ведущий научный сотрудник

SPIN-код (РИНЦ):7124-5304

Ковалев Виктор Савельевич ${ }^{1}$

д. с-х. наук, зам.директора по науке

Токмаков Сергей Вячеславович ${ }^{2}$

к.б.н., научный сотрудник

SPIN-код (РИНЦ):3196-9049

Белан Ксения Александровна ${ }^{3}$

студент

1-Всероссийский научно-исследовательский институт риса, г. Краснодар, Россия

2-Северо-Кавказский зональный научноисследовательский институт садоводства и виноградарства, г. Краснодар, Россия

3- Кафедра генетики и микробиологии, Кубанский государственный университет, Краснодар, Россия supruni@mail.ru

В ходе исследования было выполнено генотипирование 22 отечественных сортов риса современной селекции с использованием микросателлитных ДНК-маркеров. ДНК-маркеры проявили различный уровень полиморфизма - от двух до восьми аллелей на локус. Для всех изученных сортов получены уникальные SSRпрофили

Ключевые слова: РИС, МИКРОСАТЕЛЛИТНЫЕ ДНК-МАРКЕРЫ, ДНК-ПАСПОРТ, ГЕНЕТИЧЕСКОЕ РАЗНООБРАЗИЕ, АЛЛЕЛЬНЫЙ ПОЛИМОРФИЗМ

Doi: 10.21515/1990-4665-131-065
UDC $663.252 .41 \cdot 575.22$

Biology

\section{ДНК-ПАСПОРТИЗАЦИЯ СОВРЕМЕННЫХ РОССИЙСКИХ СОРТОВ РИСА С ПРИМЕНЕНИЕМ SSR-МАРКЕРОВ}

Suprun Ivan Ivanovich ${ }^{1,2}$

Cand.Biol.Sci., leader researcher

SPIN: 7124-5304

Kovalyov Viktor Savelyevich ${ }^{1}$

Dr.Sci.Agri., deputy director in science

Tokmakov Sergey Vyacheslavovich2

Cand.Biol.Sci., staff scientist

SPIN:3196-9049

Belan Kseniya Alexandrovna ${ }^{3}$

student

1-All Russian Rice Research Institute, Krasnodar,

Russia

2-North-Caucasian Zonal Research Institute of

Horticulture and Viticulture, Krasnodar, Russia

3 - Department of genetics and microbiology, Kuban

state university, Krasnodar, Russia

supruni@mail.ru

In the presented study, we have performed genotyping of modern Russian rice cultivars using microsatellite DNA-markers. The markers showed different level of allelic polymorphism: from 2 to 8 alleles per locus. For all studied cultivars,unique DNA-fingerprints were obtained

Keywords: RICE, MICROSATELLITE DNAMARKERS, DNA-PASSPORTISATION, GENETIC DIVERSITY, ALLELIC POLYMORPHISM

\title{
Введение
}

Изучение генетического разнообразия является важным научным направлением генетике культурных растений. Комплексная характеристика коллекций генетических ресурсов, анализ генетической

\footnotetext{
* Работа выполнена при поддержке РФФИ и администрации Краснодарского края (проект № 16-44-230244 p_a)
}

http://ej.kubagro.ru/2017/07/pdf/65.pdf 
структуры генофонда и оценка степени генетического родства с использованием молекулярно-генетических методов является важным этапом, необходимым для наиболее эффективного использования генетических ресурсов. Наряду с этим анализ генетического разнообразия коллекций генетических ресурсов, а также оценка степени генетического сходства групп генотипов, представляющих разные экологогеографические региона, позволяет получить важные знания для изучения филогенетических взаимосвязей микроэволюционных путей формирования генофонда на уровне вид/подвид.

К наиболее перспективным методам анализа генетического разнообразия следует отнести метод на основе анализа микросателлитных локусов (SSR). SSR-маркеры - простые повторяющиеся последовательности - широко используются в генотипировании и при конструировании генетических карт. Их широкое применение обусловлено равномерным распределением по геному, высоким полиморфизмом, кодоминантным характером наследования и воспроизводимостью результатов анализа. Эти характеристики сделали SSR-маркеры одними из наиболее часто используемых молекулярных ДНК-маркеров при анализе генетического разнообразия, картировании генов, популяционного анализа, выяснении филогенетических взаимосвязей на уровне вид/подвид/род и идентификации генотипов [1].

У риса было в результате работ Akagi et al (1996) и McCouch et al (1997) было выявлено, что относительная частота встречаемости различных повторов уменьшается с увеличением размера повтора. При этом скрининге геномной библиотеки, имевшейся в то время, выявил наличие около 5700-10000 микросателлитных последовательностей [2-4]. Последующее секвенирование генома риса позволило предположить, что общее количество микросателлитных последовательностей, составляет порядка 100000 [5]. 
Анализ мировой научной деятельности в научно-исследовательских организациях, занимающихся вопросами генетики риса, позволяет говорить о том, что данное направление исследований является актуальным в мире в настоящее время. Подтверждением этому является широкий перечень публикаций по данной тематике в мировой научной печати.

Так, к примеру, в исследовании, выполненном группой китайских и южнокорейских исследователей проанализировали 150 сортов риса, из генетических коллекций Южной Кореи, Китая и Японии. Для оценки генетических дистанций изученных групп генотипов и сравнительного анализа уровня генетического разнообразия внутри групп использовали 28 микросателлитных маркеров. Было выявлено, что наибольшим уровнем аллельного полиморфизма по изученным локусам обладает генплазма риса из Южной Кореи. Наименьшим генетическим разнообразием обладали сорта из Японии. Общий уровень генетического разнообразия внутри групп южнокорейских и китайских сортов риса был выше, чем в выборке сортов из Японии [6]. В работе другого авторского коллектива из Индии изучали генетическую структуры коллекции сортов из национального генофонда, при этом в работе были задействованы сорта разных периодов селекции - от 1970-х годов до 2000-х. Кроме того, в выборку вошло 11 стародавних сортов народной селекции. Для генотипирования использовали 64 SSR-маркера, из которых 52 оказались полиморфными в изученной выборке сортов. В результате работы получили данные о степени генетического сходства сортов в изученной выборке, и, кроме того выявили, что уровень аллельного полиморфизма увеличивался в ряду групп сортов по декадам их создания:1970-е-1980-е-1990-е-2000-е. Это, вполне вероятно может быть связано с вовлечением большего количества исходных форм в селекцию и с диверсификацией селекционных направлений [7]. 
Наряду с анализом генетической структуры коллекций сортов риса, SSR-маркеры также успешно применяются и для изучения генетического разнообразия природных популяций дикорастущих предковых видов риса [8], а также для анализа генетических взаимосвязей между современными сортами, стародавними сортами народной селекции и дикорастущими формами [9, 10].

Перечень работ по данному направлению достаточно широк, как и перечень стран, в которых аналогичные исследования выполнялись. К сожалению, до настоящего времени в России не выполнялось научноисследовательских проектов, направленных на изучение генетического разнообразия российского генофонда риса и выяснение его взаимосвязей с генофондом из других регионов мира. В связи с этим, нами поставлена задача изучить генетическое разнообразие отечественного генофонда риса с использованием микросателлитных ДНК-маркеров. На данном этапе работы выполнили SSR-генотипирование выборки из 22 современных сортов риса по 14 маркерам.

\section{Объекты и методы исследований}

Объектом исследования послужили 22 современных отечественных сорта риса селекции ВНИИриса. Образцы ДНК выделяли из свежесрезанной части листовой пластинки :растений, а также из 10-15 дневных проростков. Экстракцию ДНК проводили буфером следующего состава: 20мл 1M Tris-HCl (pH 7.5), 5 мл 5MNaCl, 5 мл 0.5MEDTA (pH 8.0), 5 мл 10\% SDS в общем объеме 100 мл. Часть листа (2-3см) растирали в 500 мкл экстрагирующего буфера в пластиковой пробирке объемом 1,5мл. Инкубировали образцы при 600С в течение 3 часов. Отделяли супернатант центрифугированием при 12000 об/мин. К перенесенной в чистую пробирку верхней фазе добавляли 500 мкл изопропанола, http://ej.kubagro.ru/2017/07/pdf/65.pdf 
оставляли для преципитации на 10-20 минут при комнатной температуре, предварительно перемешав. После этого образец центрифугировали 5 минут при 12000 об/мин, полученный осадок промывали 300мкл 70\% этанола, высушивали и растворяли в 200мкл 0,1*TЕ. В ПЦР смесь добавляли по 2,5 мкл раствора ДНК, выделенного данным методом. ПЦР проводили по стандартным методикам, но с выполнением предварительной оптимизации ряда параметров реакции [11, 12]. Генотипирование проводили с использованием 14 SSR-маркеров: RM1, RM11, RM122, RM168, RM167, RM164, RM510, RM307, RM154, RM162, RM44, RM316, RM19, RM474. Нуклеотидная последовательность праймеров доступна на сайте www.gramene.org. Маркеры были распределены в мультиплексные наборы по 3-4 маркера.

Предварительную оценку продуктов ПЦР проводили электрофорезом в 2\% агарозном геле 30-50 минут при напряжении $150 \mathrm{~V}$. В качестве красителя использовали бромистый этидий; гелевые пластины визуализировали в ультрафиолете. Анализ размеров амплифицированных фрагментов SSR - маркеров проводили на автоматическом генетическом анализаторе ABIprism 3130. Обработку данных осуществляли в программе GeneMapper 4.1. Для подсчета показателя «количество эффективных аллелей» и коэффициента Шеннона, характеризующего уровень информативности маркеров, использовали программу GenAlEx 6.5 [13], дендрограмму построили в программе PAST. Фрагментный анализ SSRмаркеров был выполнен на оборудовании ЦКП «Геномные и постгеномные технологии» ФГБНУ СКЗНИИСиВ.

\section{Результаты}

В ходе генотипирования с использованием мультиплексной ПЦР, при проведении фрагментного анализа на автоматическом генетическом анализаторе ABIprism 3130. На рисунке 1 представлены результаты 
фрагментного анализа сортов риса Привольный, Анаит и Ивушка по микросателлитным ДНК-маркерам RM 510, RM 307, RM154 и RM162, который вошли в один мультиплексный набор. Результаты представлены в рабочем интерфейсе программы GeneMapper 4.1.

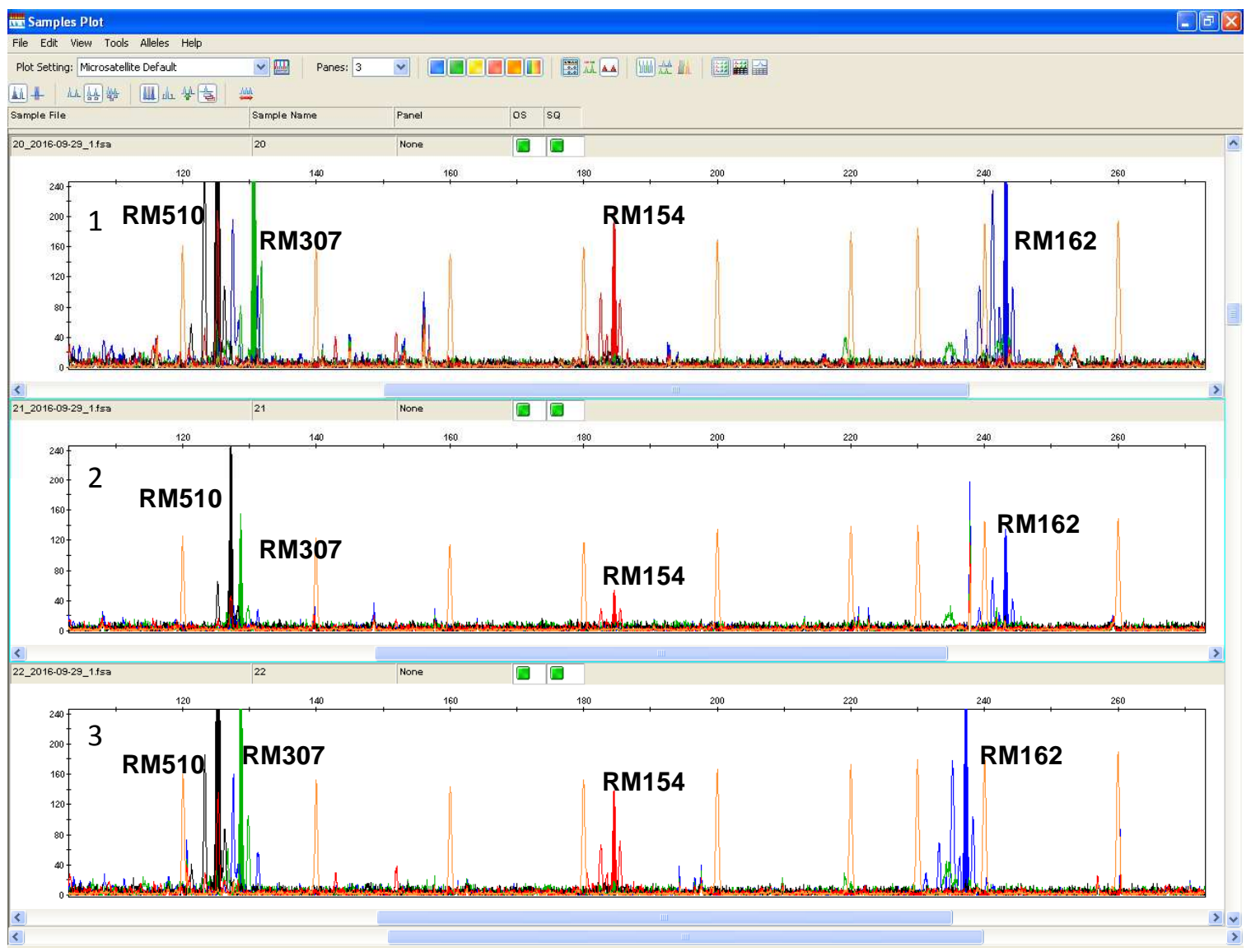

Рисунок 1. Результаты фрагментного анализа сортов риса Привольный (1), Анаит (2) и Ивушка (3) по мультиплексному набору, включающему SSRмаркеры RM 510, RM 307, RM154 и RM162.

Как видно из рисунка, для каждого из маркеров идентифицируются пики на электрофореграмме. Несмотря на близость диапазонов размером фрагментов амплификации у маркеров RM 510 и RM 307, благодаря использованию разных флуоресцентных меток для данных маркеров (черный и зеленый цвет пиков), удается безошибочно их идентифицировать. В результате работы были получены SSR- 
фингерпринты для всех сортов, задействованных в работе. ДНК фингерпринты для некоторых приведены в таблице 1.

Таблица 1 ДНК-фингерпринты изученных сортов риса по

14 SSR-маркерам

\begin{tabular}{|c|c|c|c|c|c|c|c|c|c|c|c|c|c|c|}
\hline & $\bar{\sum}$ & $\sum_{\approx}$ & $\underset{\Sigma}{\stackrel{\Xi}{\Xi}}$ & 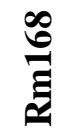 & $\frac{\hat{\sigma}}{\underline{\Xi}}$ & $\frac{\vec{\sigma}}{\mathbb{\Xi}}$ &  & 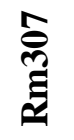 & 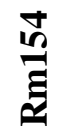 & $\frac{\tilde{\sigma}}{\tilde{g}}$ &  & & $\overrightarrow{\vec{\Xi}}$ & $\begin{array}{l}\stackrel{+}{+} \\
\stackrel{\mid}{\mid}\end{array}$ \\
\hline Лиман & 91 & 127 & 224 & 97 & 149 & 271 & 125 & 129 & 185 & 225 & 121 & 200 & 216 & 261 \\
\hline Кулон & 94 & 127 & 230 & 99 & 153 & 269 & 123 & 131 & 189 & 225 & 121 & 200 & 216 & 261 \\
\hline Старт & 93 & 127 & 224 & 97 & 149 & 271 & 125 & 129 & 184 & 225 & 121 & 200 & 216 & 261 \\
\hline Рапан & 93 & 127 & 230 & 97 & 149 & 305 & 125 & 129 & 185 & 225 & 121 & 200 & 216 & 261 \\
\hline Лидер & 93 & 133 & 230 & 99 & 149 & $\begin{array}{l}259: \\
298\end{array}$ & 125 & 129 & 185 & 237 & 117 & 200 & 216 & 261 \\
\hline Регул & 100 & 127 & 230 & 97 & 149 & 290 & 125 & 131 & 193 & 243 & 113 & 200 & 216 & 261 \\
\hline Янтарь & 100 & 133 & 228 & 97 & 149 & 290 & 125 & 129 & 185 & 243 & 117 & 200 & 216 & 261 \\
\hline Сонет & 93 & 127 & 226 & 98 & 149 & 305 & 125 & 129 & 185 & 243 & 121 & 202 & 216 & 261 \\
\hline Привольный & 100 & 127 & 230 & 97 & 149 & 271 & 125 & 131 & 185 & 243 & 121 & 200 & 216 & 261 \\
\hline Анаит & 100 & 127 & 230 & 97 & 149 & 271 & 127 & 129 & 185 & 243 & 123 & 200 & 216 & 261 \\
\hline Ивушка & 96 & 127 & 229 & 97 & 149 & 298 & 125 & 129 & 185 & 237 & 121 & 200 & 216 & 263 \\
\hline Серпантин & 96 & 127 & 229 & 99 & 149 & 298 & 125 & 129 & 185 & 237 & 121 & 200 & 216 & 259 \\
\hline Соната & 93 & 127 & 228 & 98 & 149 & 259 & 125 & 129 & 185 & 204 & 121 & 200 & 219 & 257 \\
\hline Фаворит & 100 & 127 & 228 & 97 & 149 & 290 & 125 & 129 & 185 & 247 & 93 & 200 & 216 & 261 \\
\hline Снежинка & 93 & 134 & 226 & 97 & 129 & 298 & 123 & 131 & 191 & 204 & 93 & 200 & 216 & 261 \\
\hline Ренар & 93 & 127 & 230 & 97 & 149 & 290 & 125 & 131 & 193 & 225 & 117 & 200 & 216 & 261 \\
\hline Визит & 96 & 133 & 230 & 99 & 149 & 298 & 125 & 129 & 185 & 237 & 117 & 200 & 216 & 261 \\
\hline Славянец & 93 & 127 & 224 & 97 & 149 & 269 & 125 & 129 & 185 & 237 & 117 & 200 & 216 & 261 \\
\hline Олимп & 100 & 127 & 228 & 97 & 145 & 271 & 125 & 129 & 185 & 237 & 117 & 200 & 216 & 261 \\
\hline Дружный & 93 & 127 & 230 & 97 & 145 & 298 & 125 & 129 & 185 & 243 & 117 & 200 & 216 & 261 \\
\hline Вираж & 93 & 127 & 224 & 97 & 145 & 271 & 125 & 129 & 189 & 225 & 123 & 200 & 216 & 261 \\
\hline Полевик & 93 & 127 & 230 & 97 & 149 & 301 & 125 & 129 & 185 & 225 & 119 & 200 & 216 & 261 \\
\hline
\end{tabular}

Как видно из таблицы 1, каждый из сортов обладает уникальным SSR-фингерпринтом. При этом очевидно, что маркеры проявили различный уровень полиморфизма. Количество аллелей, выявленных по использованным в работе SSR-маркерам варьировало от двух аллелей на локус - по маркерам RM1, RM316, RM19 и RM307 до восьми аллелей на локус - по маркеру RM164. Для оценки информативности использованных в работе SSR-маркеров рассчитали показатели количество эффективных 
аллелей и индекс информативности Шеннона. Они представлены в таблице 2.

Таблица 2 Анализ информативности, использованных в работе SSRмаркеров

\begin{tabular}{|c|c|c|c|c|}
\hline p & $\mathbf{N}^{*}$ & $\mathbf{N a}$ & $\mathrm{Ne}$ & I \\
\hline RM1 & 22 & 5,000 & 2,881 & 1,25 \\
\hline RM11 & 22 & 2,000 & 1,424 & 0,474 \\
\hline $\mathbf{R M}$ & 22 & 5,000 & $\mathbf{3 , 4 5 7}$ & \\
\hline $\mathbf{R M}$ & 22 & 0 & & \\
\hline & & 4,000 & & 0,10 \\
\hline & 2 & 0 & 0 & 1 \\
\hline & & 0 & 1,322 & \\
\hline & 22 & $2,($ & 41 & 0 , \\
\hline & 2 & 0 & 1,820 & 0,9 \\
\hline & 22 & 5,000 & 3,841 & 1,4 \\
\hline & 22 & 6,000 & $\mathbf{3 , 4 5 7}$ & 1,4 \\
\hline & 22 & 2,000 & 1,095 & \\
\hline & 22 & 2,000 & 1,095 & \\
\hline M47 & 22 & 4,000 & 1,330 & 0,5 \\
\hline
\end{tabular}

*N - количество образцов в выборке,

$\mathrm{Na}-$ количество аллелей,

$\mathrm{Ne}-$ количество эффективных аллелей,

I - индекс информативности Шеннона.

Как видно из таблицы, SSR-маркеры проявили различный уровень аллельного полиморфизма. При этом следует отметить, что один их маркеров в группе маркеров, проявивших более высокий уровень полиморфизма (5 и более аллелей на локус) - это RM154, обладает более низкими показателями «количество эффективных аллелей» и индекс информативности Шеннона. Это связано с неравномерным распределением частот встречаемости его аллелей в изученной выборке образцов. Несмотря на то, что по нему было идентифицировано 5 аллелей, два из них встречаются всего по одному разу, а еще два - по два раза в 
изученной выборке генотипов. На долю аллели с размером фрагмента 185 п.н. приходится $72 \%$ образцов из изученной выборки.

На основе полученных данных нами было также выполнен кластерный анализ изученных сортов (рисунок 2).

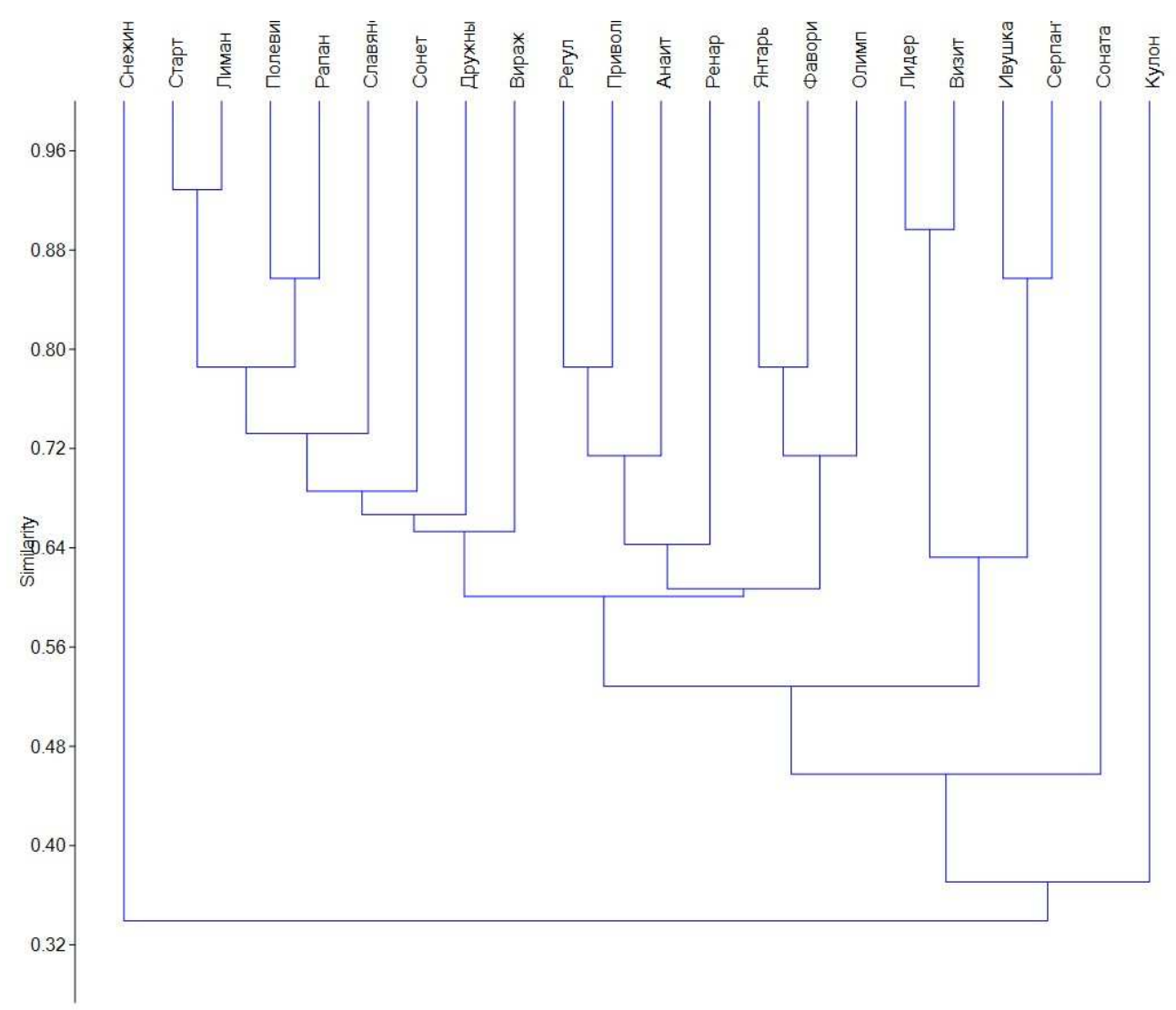

Рисунок 2 UPGMA кластеризация изученных сортов риса

В целом, результаты кластеризации отразили гетерогенность изученной выборки сортов, в которую вошли сорта с разным морфотипом, длиной вегетационного периода, а также длиной зерновки. Примечательно, что длиннозерный сорт Снежинка, выделен в отдельную ветвь кластера на уровне с минимальным показателем генетического сходства с изученными сортами. Это может быть связано со значительным уровнем присутствия в его ДНК-профиле аллелей, специфичных для подвида indica.

Таким образом, в результате выполненной работы было выполнено SSR-генотипирование 22 современных сортов риса российской селекции, http://ej.kubagro.ru/2017/07/pdf/65.pdf 
для всех изученных сортов получены уникальные ДНК-фингерпринты и выполнена оценка уровня полиморфизма использованных в работе SSRмаркеров. В дальнейшем нами планируется расширение выборки используемых SSR-маркеров и проведение масштабного анализа генетического разнообразия отечественных генетических коллекций риса что позволит изучить их генетическую структуру и получить ДНКпаспорта сортов.

\section{Литература}

1. Хавкин Э.Е. Молекулярные маркеры в растениеводстве / Э.Е Хавкин // Сельскохозяйственная биология, 1997.- №5.- С.3-19.

2. Wu K.S. Abundance, polymorphism and genetic mapping of microsatellites in rice/ K.S. Wu, S.D. Tanksley // Mol. Gen. Genet., 1993.-V.241.- P. 225-235.

3. Akagi $\mathrm{H}$. Microsatellite DNA markers for rice chromosomes / H. Akagi, Y. Yokozeki, A. Inagaki, T. Fujimura // Theor. Appl. Genet., 1996.- V. 93.- P. 1071-1077.

4. McCouch S.R. Microsatellite marker development, mapping and applications in rice genetics and breeding / S.R. McCouch, X. Chen, O. Panaud., et al. // Plant Mol. Biol., 1997. V.35.- P. 89-99.

5. McCouch S.R. Microsatellite markers in rice: abundance, diversity, and applications/ S.R. McCouch, S. Temnykh, A. Lukashova, et al. // Rice genetic 4. Proceeding of the fourth international rice genetic symposium.- Los Banos., 2001.- P. 117-135.

6. Weiguo Z., Jong-Wook C., Kyung-Ho Ma et al. Analysis of Genetic Diversity and Population Structure of Rice Cultivars from Korea, China and Japan using SSR Markers/ Z.Weiguo, C. Jong-Wook, Kyung-Ho Ma. et al // Genes and Genomics, 2009.- V. 31.- № 4.P. 283-292.

7. Choudhary G, Ranjitkumar N, Surapaneni M, Deborah DA, Vipparla A, et al. (2013) Molecular Genetic Diversity of Major Indian Rice Cultivars over Decadal Periods. PLoS ONE 8(6): e66197. doi:10.1371/journal.pone.0066197.

8. L.-Z.Gao. Comparisons of microsatellite variability and population genetic structure of two endangered wild rice species, Oryza rufipogon and O. officinalis, and their conservation implications/ L.-Z.Gao, C.-H. Zhang // Biodiversity and Conservation, 2005.- V. 14. - P. 1663-1679.

9. Michael J. Thomson. Genetic diversity analysis of traditional and improved Indonesian rice (Oryza sativa L.) germplasm using microsatellite markers/Michael J. Thomson, Endang M. Septiningsih, Fatimah Suwardjo. et al. // Theor Appl Genet, 2007.- V. 114. P. 559-568.

10. Basabdatta Das. Genetic diversity and population structure of rice landraces from Eastern and North Eastern States of India/ Basabdatta Das, Samik Sengupta, Swarup K. Parida //BMC Genetics, 2013. V. 14. P. 71.

11. Шибата Д.К. Полимеразная цепная реакция и молекулярно-генетический анализ биоптатов // Молекулярная клиническая диагностика.- М.: Мир, 1999.- С. 395427.

12. Супрун И.И. Апробация мультиплексного SSR-анализа для ДНКпаспортизации сортов риса / И.И. Супрун, В.С. Ковалев // Политематический сетевой электронный научный журнал Кубанского государственного аграрного университета

http://ej.kubagro.ru/2017/07/pdf/65.pdf 
(Научный журнал КубГАУ) [Электронный ресурс]. - Краснодар: КубГАУ, 2015. №10(114). С. 1417 - 1427.- Режим доступа: http://ej.kubagro.ru/2015/10/pdf/103.pdf.

13. Peakall, R. and Smouse P.E. (2012) GenAlEx 6.5: genetic analysis in Excel. Population genetic software for teaching and research-an update. Bioinformatics 28, 25372539.

\section{References}

1. Khavkin E.E. Molecularnye marker $\mathrm{v}$ rastenievodstve / E.E. Havkin // sel'skochozyaistvennaya biologiya, 1997.- №5.- S.3-19.

2. Wu K.S. Abundance, polymorphism and genetic mapping of microsatellites in rice/ K.S. Wu, S.D. Tanksley // Mol. Gen. Genet., 1993.-V.241.- P. 225-235.

3. Akagi H. Microsatellite DNA markers for rice chromosomes / H. Akagi, Y. Yokozeki, A. Inagaki, T. Fujimura // Theor. Appl. Genet., 1996.- V. 93.- P. 1071-1077.

4. McCouch S.R. Microsatellite marker development, mapping and applications in rice genetics and breeding / S.R. McCouch, X. Chen, O. Panaud., et al. // Plant Mol. Biol., 1997. V.35.- P. 89-99.

5. McCouch S.R. Microsatellite markers in rice: abundance, diversity, and applications/ S.R. McCouch, S. Temnykh, A. Lukashova, et al. // Rice genetic 4. Proceeding of the fourth international rice genetic symposium.- Los Banos., 2001.- P. 117-135.

6. Weiguo Z., Jong-Wook C., Kyung-Ho Ma et al. Analysis of Genetic Diversity and Population Structure of Rice Cultivars from Korea, China and Japan using SSR Markers/ Z.Weiguo, C. Jong-Wook, Kyung-Ho Ma. et al // Genes and Genomics, 2009.- V. 31.- № 4.P. 283-292.

7. Choudhary G, Ranjitkumar N, Surapaneni M, Deborah DA, Vipparla A, et al. (2013) Molecular Genetic Diversity of Major Indian Rice Cultivars over Decadal Periods. PLoS ONE 8(6): e66197. doi:10.1371/journal.pone.0066197.

8. L.-Z.Gao. Comparisons of microsatellite variability and population genetic structure of two endangered wild rice species, Oryza rufipogon and O. officinalis, and their conservation implications/ L.-Z.Gao, C.-H. Zhang // Biodiversity and Conservation, 2005.- V. 14. - P. 1663-1679.

9. Michael J. Thomson. Genetic diversity analysis of traditional and improved Indonesian rice (Oryza sativa L.) germplasm using microsatellite markers/Michael J. Thomson, Endang M. Septiningsih, Fatimah Suwardjo. et al. // Theor Appl Genet, 2007.- V. 114. P. 559-568.

10. Basabdatta Das. Genetic diversity and population structure of rice landraces from Eastern and North Eastern States of India/ Basabdatta Das, Samik Sengupta, Swarup K. Parida //BMC Genetics, 2013. V. 14. P. 71.

11 Shibata D.K. Polimeraznaya tcepnaya reaktciya i molekularno-geneticheskiy analiz bioptatov // molekularnaya klinicheskaya diagnostika.-M.: Mir, 1999.- P. 395-427.

12. Suprun I.I. Aprobatsiya multiplexnogo SSR-analiza dlya DNA-pasportizatcii sortov risa / I.I. Suprun, V.S. Kovalyov// Polytemeticheskyi setevoy electronniy zhurnal Kubanskogo gosudrstvennogo agrarnogo universiteta (Nauchiy zhurnal KubGAU)Krasnodar: KubGAU, 2015. - №10(114). C. 1417 - 1427.- Rezhim dostupa: http://ej.kubagro.ru/2015/10/pdf/103.pdf.

13. Peakall, R. and Smouse P.E. (2012) GenAlEx 6.5: genetic analysis in Excel. Population genetic software for teaching and research-an update. Bioinformatics 28, 25372539. 